\title{
Bench cutting tests and analysis for harvesting hemp stalk
}

\author{
Shen Cheng ${ }^{1,2}$, Zhang Bin ${ }^{1}$, Li Xianwang ${ }^{1}$, Yin Guodong ${ }^{2}$, \\ Chen Qiaomin ${ }^{1 *}$, Xia Chunhua ${ }^{1}$ \\ (1. Nanjing Research Institute for Agricultural Mechanization, Ministry of Agriculture, Nanjing 210014, China; \\ 2. School of Mechanical Engineering, Southeast University, Nanjing 211189, China)
}

\begin{abstract}
As a study basis in the field of design and research of harvester prototype, bench cutting test is to provide best parameters for the cutter design. In order to obtain the optimal parameters of cutter of the hemp harvester, cutting tests on hemp stalk were conducted to examine the influences of different geometrical parameters (length and edge type) of blade, different cutting speeds and stalk feeding speeds of reciprocating single movable blade and reciprocating double movable blades on the cutting performances (cutting power, cutting quality and synthesis score) by using self-designed test bench. According to features of different test factors, multi-factors orthogonal test was applied to determine the best combination of blade length, blade edge type and number of movable blade. Then with these parameters fixed, the optimal parameters for the factors of cutting speed and stalk feeding speed were obtained by quadratic-regression rotatable orthogonal test. According to the test results, the best combination of hemp stalk cutting was that using cutter with reciprocating double movable blades of long $(120 \mathrm{~mm})$ and serrated-edge at cutting speed of $1.1704 \mathrm{~m} / \mathrm{s}$ and stalk feeding speed of $0.7079 \mathrm{~m} / \mathrm{s}$. The tests and analysis results can be applied into subsequent related researches on hemp harvesters.
\end{abstract}

Keywords: hemp stalk, hemp harvester, blade, bench cutting test, cutter design

DOI: $10.25165 /$ j.ijabe.20171006.3475

Citation: Shen C, Zhang B, Li X W, Yin G D, Chen Q M, Xia C H. Bench cutting tests and analysis for harvesting hemp stalk. Int J Agric \& Biol Eng, 2017; 10(6): 56-67.

\section{Introduction}

Hemp, referring in particular to industrial hemp in this paper, is a kind of crop for fiber or oil use different from marijuana as its tetrahydrocannabinol (THC)

\footnotetext{
Received date: 2017-07-20 Revision date: 2017-10-08

Biographies: Shen Cheng, PhD candidate, Assistant Professor, research interests: agricultural mechanization engineering, Email: shencheng1989@cau.edu.cn; Zhang Bin, Associate Professor, research interests: agricultural mechanization engineering, Email: xtsset@hotmail.com; Li Xianwang, Professor, research interests: agricultural mechanization engineering, Email: xw3871@163.com; Yin Guodong, PhD, Professor, research interests: vehicle engineering, Email: ygd@seu.edu.cn; Xia Chunhua, Associate Professor, research interests: agricultural mechanization engineering, Email: xiachunhua@caas.cn.

*Corresponding author: Chen Qiaomin, Professor, research interests: agricultural mechanization engineering. Director's Office, Nanjing Research Institute for Agricultural Mechanization, Ministry of Agriculture, No.100 Liuying, Xuanwu District, Nanjing 210014, China. Tel: +86-25-84346264, Email: nnncqm@163.com.
}

content is lower than $0.3 \%{ }^{[1]}$. It mainly grows in China, Canada, and Europe ${ }^{[2,3]}$. As a stalk fiber crop, hemp fiber plays an important role in the fields of papermaking, building, and especially textile ${ }^{[4-6]}$. Characterized by comfort, moisture absorption, bacterial inhibition, heat resistance, and anti-static property ${ }^{[6]}$, hemp fiber textiles have been increasingly received and valued by the public at home and abroad, and the hot trend of studying and developing hemp has been created in Europe and America $^{\text {[7] }}$. China is one of the earliest countries to plant and utilize hemp ${ }^{[8]}$, as well as the country with the largest hemp cultivation area around the world at present ${ }^{[9]}$. Compared with Europe and America, however, China has relatively low mechanization degree in harvesting, which is seriously disjointed with the hemp production requirements ${ }^{[10]}$. During recent five years, China's cultivation area of fiber crops like hemp has been decreased year by year ${ }^{[11]}$. As for the major reason, the rise of labor cost has resulted in the increase of hemp 
harvesting cost, which further restrains the hemp growers' enthusiasm of expanding the cultivation scale. Hence, the industry development has encountered the bottleneck of mechanization level restriction ${ }^{[12,13]}$, and the problem of mechanized harvesting for hemp has to be settled urgently. Study on mechanized harvesting technique of hemp is forward-looking in China ${ }^{[14]}$, so it is necessary to carry out the fundamental research on hemp harvesting in the primary study in this field, such as research on hemp cutter.

In the process of studying on the cutting performance of crop stalk, if prototype is directly used to examine cutting performance in the farm field test, it will lead to issues like low repeatability of test, complex influence condition in farm field, poor working condition of sensor, low collection accuracy, and test is easily affected by season and farm field. Therefore, some scholars have developed the indoor cutting benches, and carried out cutting tests for stalk crop like ramie, rice, sugar cane, corn and so on ${ }^{[15-23]}$.

In terms of stalk, the cutting process is affected by various factors, such as its physical property and quality of cutter like material of the cutter, geometric shape of cutting edge of blade ${ }^{[24]}$. In addition, some scholars studied and found that except for energy consumption, cutting speed is strongly related to the cutting quality. Thus, to obtain the best cutter parameters ${ }^{[25,26]}$ through test is the foundation for the further research and development of prototype.

Base on the above, cutting tests of indoor bench was performed to hemp stalk, aimed at providing optimal parameters ${ }^{[27]}$ in the design of cutter of prototype.

\section{Materials and methods}

\subsection{Test equipment and material}

\subsubsection{Test bench}

Self-designed and trial-produced stalk cutting bench $^{[26]}$ was applied in the tests. The bench is composed of cutting bench, stalk feeding bench and measurement and control system, as shown in Figure 1. Its concrete technical parameters are as shown in Table 1. Cutting bench can test cutters with different parameters at different cutting speeds of $0-2 \mathrm{~m} / \mathrm{s}$; stalk feeding bench can provide the speed at $0-2 \mathrm{~m} / \mathrm{s}$; measurement and control system can regulate and control the cutting speed and stalk feeding speed and record the data of cutting driving force, torque and power consumption.

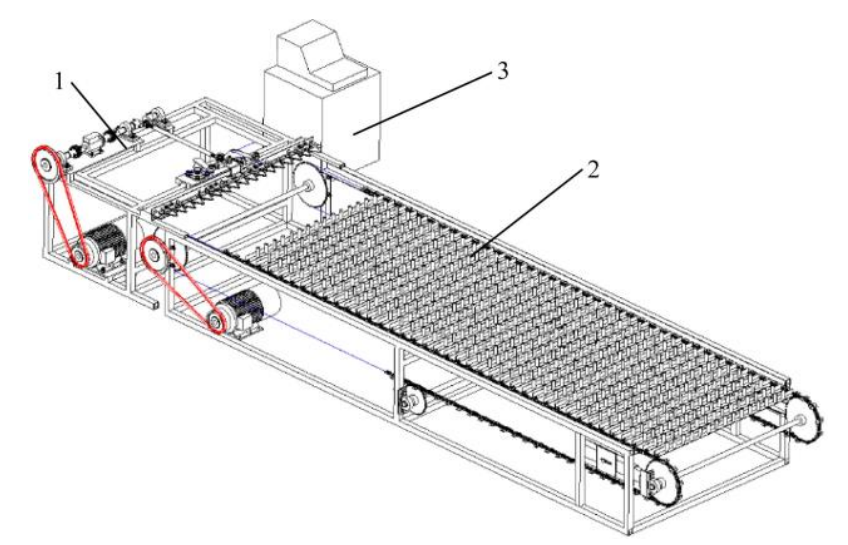

1. Cutting bench 2. Stalk feeding bench 3. Measurement and control system Figure 1 Structure schematic of hemp stalk cutting test bench

Table 1 Parameters of hemp stalk cutting test bench

\begin{tabular}{lc}
\hline \multicolumn{1}{c}{ Parameters } & Values \\
\hline Cutting speed $/ \mathrm{m} \cdot \mathrm{s}^{-1}$ & $0-2$ \\
Stalk feeding speed $/ \mathrm{m} \cdot \mathrm{s}^{-1}$ & $0-2$ \\
Power of cutting $/ \mathrm{kW}$ & 4 \\
Power of stalk feeding $/ \mathrm{kW}$ & 3 \\
Cutting width $/ \mathrm{mm}$ & 1200 \\
Cutting height $/ \mathrm{mm}$ & 100 \\
Torque range $/ \mathrm{N} \cdot \mathrm{m}$ & $\pm 20( \pm 0.2)$ \\
Tension force range/N & $\pm 5000( \pm 1)$ \\
Acquisition frequency $/ \mathrm{kHz}$ & 10 \\
\hline
\end{tabular}

Double chutes of spatial crank-rocker-slider structure is applied in the key structure of test bench cutting transmission mechanism (Figure 2a), and its kinematic diagram is as shown in Figure 2b. In this mechanism, reciprocating motion is implemented in upper and lower cutting blades of cutter, with same speed and opposite direction, and its cutting form is double-blade cutting. If rocker CD'E' of lower cutting knife is dismounted and lower cutting blade is fixed, this mechanism can still drive rocker CDE of upper cutting blade and make it do the reciprocating motion. At this moment, cutting form of the mechanism is single-blade cutting.

\subsubsection{Test material}

The crop of "Wan Dama \#1 (Anhui Hemp No.1)" planted in Lu'an Hemp Comprehensive Test Station of China Agriculture Research System for Bast and Leaf Fiber Crops was selected and its collection time was July $16^{\text {th }}, 2016$. 

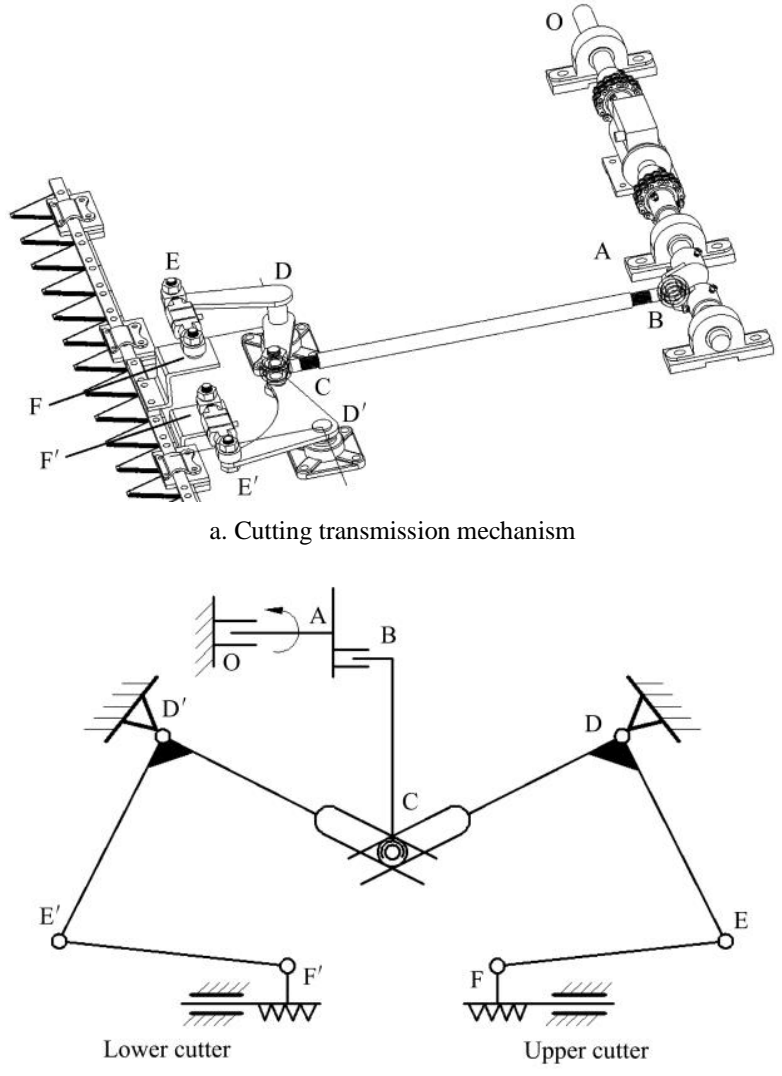

b. Kinematic diagram of mechanism

Figure 2 Cutting transmission mechanism and kinematic diagram

In order to ensure other factors were stable except for test elements, the selected hemp were divided into three classes: thin $(\Phi<12 \mathrm{~mm})$, medium $(12 \mathrm{~mm} \leq \Phi \leq 18 \mathrm{~mm})$, thick $(\Phi>18 \mathrm{~mm})$, and different classes were averagely distributed into different test groups. Because the distribution of hemp in farm field were ever investigated before the test, and average hemp stalks in hemp ridge during harvesting was 38.57 per square meter, 40 hemp stalks are regularly chosen in $1 \mathrm{~m}^{2}$ on the stalk feeding bench in each test during the bench tests.

\subsection{Test method}

\subsubsection{Selection of test factors}

In the cutting test using indoor bench, influence of different cutting speed and hemp stalk feeding speed on the cutting performance was studied under geometric parameters of different blades of reciprocating single movable blade and double movable blades. For study on the field of hemp mechanized harvest is forward-looking, and even research on the cutting part is still at the starting stage ${ }^{[28,29]}$, general blades were mainly chosen in the experimental studies on geometric parameters. In this study, experimental research was conducted on the blades currently used in grain harvester and corn harvester, and the four chosen groups of blades is as shown in Figure 3. Four groups of selected blades were inter-combination of blades with two lengths (81 $\mathrm{mm}$, widely applied in the grain harvester and $120 \mathrm{~mm}$, widely applied in the crop harvester) and two types of blade edge (smooth-edge blade and serrated-edge blade). Width of all blades was same, i.e. $76 \mathrm{~mm}$, which was equal to the driven distance of cutter arm of the bench. Therefore, geometric parameters of four groups of selected blades could be divided into two factors: blade length and blade edge type.
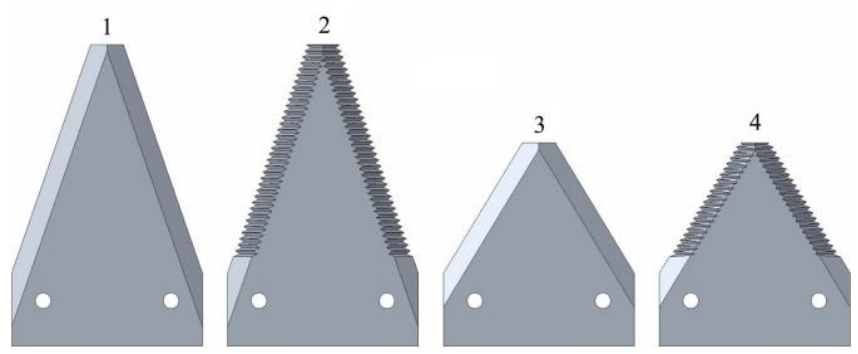

1. Long blade with smooth edge 2 . Long blade with serrated edge 3 . Short blade with smooth edge 4 . Short blade with serrated edge

Figure 3 Four kinds of blades used in test

Based on above, five designed factors in the test were cutting speed, stalk feeding speed, blade edge type, blade length and number of movable blade. Because width of blades was same, different blade lengths represented different slip cutting angles. Longer the blade is, smaller the slip cutting angle is, and vice versa.

\subsubsection{Establishment of appraisal indexes}

Bench test is the basic research part of design of harvester prototype, aimed at theoretically providing optimal parameters in design of cutter of prototype, so its appraisal indexes are mutually connected with the indicators of cutting performance of harvester prototype. According to the condition of bench test and requirement of prototype performance indexes, energy consumption and cutting quality were mainly estimated in terms of cutting part, so the determined appraisal indexes were cutting power and number of failed stubbles (no cutting off or phloem tearing) and smaller indexes will be better. In addition, for many applied appraisal indexes will mutually contradict, the appraisal model would be built based on numerous indicators and score would be applied to comprehensively reflect the multiple index value.

'Weight allocation' was applied in the establishment 
of scoring model. In order to make the score more visualized and optimized, the non-dimensional score model was set up as follows:

$$
\left\{\begin{array}{l}
\mathrm{z}_{i}=100-\frac{w_{x} \cdot\left[x_{i}-\min (x)\right]}{\max (x)-\min (x)}-\frac{w_{y} \cdot\left[y_{i}-\min (y)\right]}{\max (y)-\min (y)} \\
w_{x}+w_{y}=100
\end{array}\right.
$$

where, $z_{i}$ is the test score of level combination of group $i$; $x_{i}$ is the test value of cutting power of level combination of group $i ; y_{i}$ is the test value of number of failed stubbles of level combination of group $i ; \min (x)$ is the minimum test value of cutting power of all level combination in the test; $\max (x)$ is the maximum test value of cutting power of all level combination in the test; $\min (y)$ is the minimum text value of number of failed stubbles of all level combination in the test; $\max (y)$ is the maximum text value of number of failed stubbles of all level combination in the test; $w_{x}$ is the weight of cutting power factors; $w_{y}$ is the weight of factors of number of failed stubbles.

For study on field of hemp harvester is forward-looking, and research on cutting parameters is still at the starting stage ${ }^{[28,29]}$, it is more important to ensure the rate of cutting success of prototype than to ensure its energy-saving optimization. Thus, in the paper, weight $w_{x}$ of factor of cutting power was set as 40, and weight $w_{y}$ of factor of number of failed stubbles was set as 60 .

In summary, appraisal indexes of the test are cutting power, cutting quality (number of failed stubbles) and synthesis score.

\subsubsection{Test arrangement}

Among the five factors, blade edge type, blade length and number of movable blades are obtained by type selection with two levels, and cutting speed and stalk feeding speed are continuous variables. Therefore, according to features of different factors, multi-factors orthogonal test was applied in the bench tests to determine the best parameters of two-level factors, and then the optimal parameters of factors of cutting speed and stalk feeding speed were obtained by quadratic-regression rotatable orthogonal test.

\subsubsection{Test steps}

Tests were orderly implemented in accordance with multi-factors orthogonal test and quadratic-regression rotatable orthogonal test. Before the test, connection of various parts, data collection system and communication system should be checked whether normal or not; hemp stalk would be inserted in stalk clamping hole on stalk feeding bench and be tightened and fixed by the rubber stopper. In the test, 40 hemp stalks were selected for each test group, and the arrangement of hemp stalks in the stalk feeding bench within the area of $1 \mathrm{~m}^{2}$ was shown as Figure 4a; power of cutting bench was initiated to regulate the cutting speed of cutter and make it be equal to the required one; data collection channel was opened and computer was ready to collect and record the data; feeding transmission speed of stalk feeding bench was regulated, and hemp stalk would feed into the cutter and finish the cutting process at the required speed in the test. Information like torque of cutting process was collected and recorded by data collection system; power of cutting bench was off, jogging transmission bench, and then hemp stubble (as shown in Figure 4b) would return to the upper layer of the bench and number of failed stubbles would be counted and recorded; at the end of each group of test, hemp stubble on the bench and ground should be cleaned up, and each level combination was repeated for three times. Cutting parameters should be replaced after the storage of information. Test was continuously carried on in accordance the above designed operation sequence.

In the cutting process, the data collection system acquired and recorded torque signals of torque sensor in time (Figure 5). Besides, the cutting power was gained and recorded through follow-up processing for torque data (Equation (2)). The swath in every group of tests is $1 \mathrm{~m}$, so the cutting power recorded every time is the cutting power less than $1 \mathrm{~m}$ swath.

$$
P=\frac{\omega \cdot \int M(t) d t}{T}
$$

which, $P$ means the cutting power, $\mathrm{W} ; \omega$ indicates the crank rotational angular speed of cutting transmission mechanism, $\mathrm{rad} / \mathrm{s} ; M(t)$ denotes the undulant curve of torque timely gained from the torque sensor, $\mathrm{N} \cdot \mathrm{m} ; t$ is the time variable, s; $T$ represents the total cutting time, $\mathrm{s}$. 


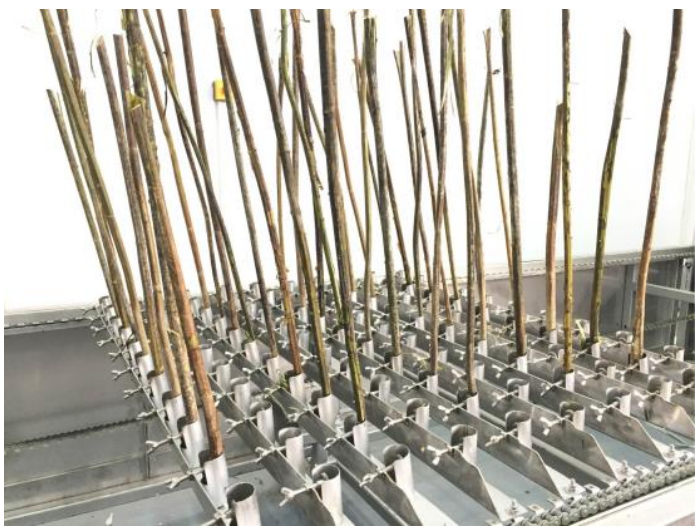

a. Distribution of hemp stalks in cutting test

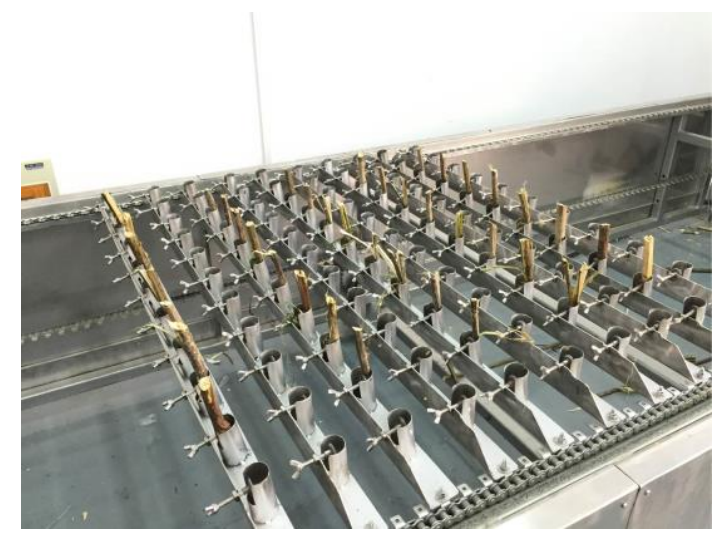

b. Hemp stubble after cutting on the bench

Figure 4 Hemp stalk and stubble on the bench

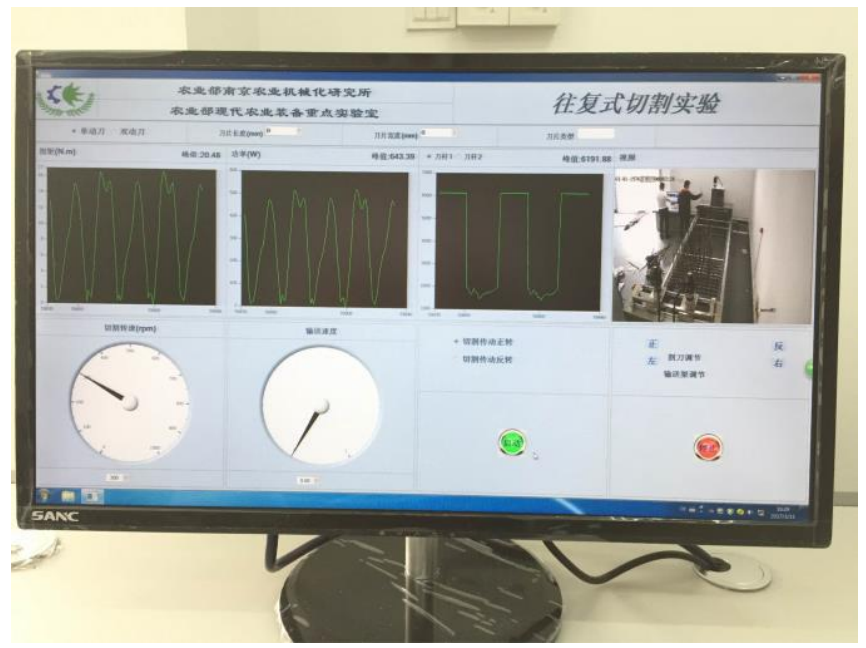

Figure 5 Real-time recording software of torque sensor

\section{Multi-factors orthogonal test}

\subsection{Determination of factors and levels and orthogonal table}

Taken cutting speed $(A)$, stalk feeding speed $(B)$, blade edge type $(C)$, blade length $(D)$, number of movable blade $(E)$ as the test factors, and the factors and levels are shown in Table 2. The test was aimed at examining the interaction between cutting speed $(A)$ and stalk feeding speed $(B)$. For five factors were two levels, two-level orthogonal table was selected in the test. Sum of degree of freedom of five factors and interaction was:

$$
\begin{aligned}
& f_{A}+f_{B}+f_{C}+f_{D}+f_{E}+f_{A \times B} \\
& =1+1+1+1+1+1+1=6
\end{aligned}
$$

Lines of the selected orthogonal table should meet: $n \geq 6+1=7$, so $L_{8}\left(2^{7}\right)$ was chosen.

Table 2 Factors and levels of orthogonal tests

\begin{tabular}{lcc}
\hline \multicolumn{1}{c}{ Factors/Levels } & Level 1 & Level 2 \\
\hline$A$ : Cutting speed & High $\left(1.2 \mathrm{~m} \cdot \mathrm{s}^{-1}\right)$ & Low $\left(0.8 \mathrm{~m} \cdot \mathrm{s}^{-1}\right)$ \\
$B$ : Stalk feeding speed & high $\left(0.9 \mathrm{~m} \cdot \mathrm{s}^{-1}\right)$ & low $\left(0.6 \mathrm{~m} \cdot \mathrm{s}^{-1}\right)$ \\
$C:$ Blade edge type & Smooth & Serrated \\
$D:$ Blade length & Long $(120 \mathrm{~mm})$ & Short $(81 \mathrm{~mm})$ \\
$E:$ Number of movable blade & Double & Single \\
\hline
\end{tabular}

\subsection{Results and analysis}

\subsubsection{Cutting power}

Result of cutting power in each group of orthogonal test and variance calculation for given repeat tests is shown in Table 3; ANOVA of cutting power is as shown in Table 4. By ANOVA of test result of cutting power, factors $A$ and $E$ were significant in significance level 0.01 , while factors $B, C, D$ and interaction $A \times B$ were not significant. It was shown in results that cutting speed and number of movable blade were main factors for cutting power, while effect of stalk feeding speed, blade edge type, blade length and interaction between cutting speed and stalk feeding speed were not significant on cutting power. The level combination of best and smallest cutting power was $E 1 A 2$ i.e. double-movable blade, and low cutting speed should be applied for cutting.

It was shown in the experimental results that driven power of cutter itself to a large extent could determine the power of cutter in the process of cutting hemp. Faster the cutting speed is, larger the cutting power is; when using the group of double movable blade, it could drive one more group of movable blade than that of single blade group, and the mass of driven movable blade was twice of single movable blade group, but under the same cutting speed, the speed of single blade of double movable blades was half of that of single movable blade. For kinetic energy of cutter was proportional to its mass and quadratic of speed, the driven power of single movable blade group was larger. 
Table 3 Variances calculation for cutting power and number of failed stubbles

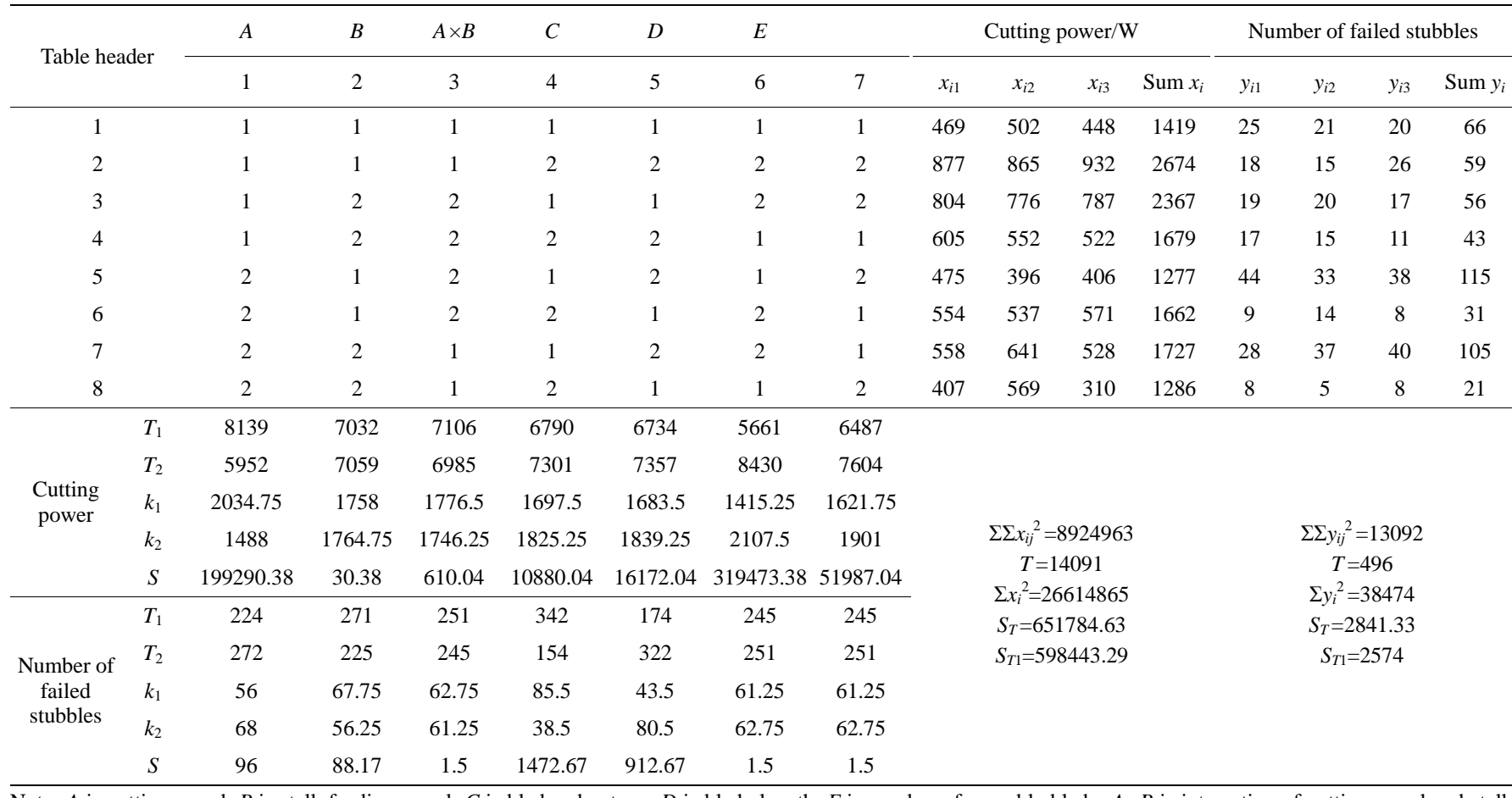

Note: $A$ is cutting speed, $B$ is stalk feeding speed, $C$ is blade edge type, $D$ is blade length, $E$ is number of movable blade, $A \times B$ is interaction of cutting speed and stalk feeding speed, $x_{i j}$ is the cutting power value of $i$ th test level combination and $j$ th repeated test, $y_{i j}$ is the number of failed stubbles of $i$ th test level combination and $j$ th repeated test, $x_{i}$ is the sum value of cutting power of $i$ th test level combination, $y_{i}$ is the sum value of number of failed stubbles of $i$ th test level combination, $T$ is sum of test value, $S_{T}$ is total sum of deviation squares, $S_{T 1}$ is sum of deviation squares of each column, $T_{1}$ is sum of level $1, T_{2}$ is sum of level $2, k_{1}$ is average of level $1, k_{2}$ is average of level 2, $S$ is sum of deviation squares. The same below.

Table 4 ANOVA for cutting power and number of failed stubbles

\begin{tabular}{|c|c|c|c|c|c|c|c|}
\hline \multirow{2}{*}{ source } & \multicolumn{2}{|c|}{ Sum of squares } & \multirow{2}{*}{$d f$} & \multicolumn{2}{|c|}{ Mean square } & \multicolumn{2}{|r|}{$F$ - ratio } \\
\hline & Cutting power & Number of failed stubbles & & Cutting power & Number of failed stubbles & Cutting power & Number of failed stubbles \\
\hline$A$ & 199290.38 & 96 & 1 & 199290.38 & 96 & $32.17 * * *$ & $6.07 * *$ \\
\hline$B$ & 30.38 & 88.17 & 1 & 30.38 & 88.17 & 0.00 & $5.57 * *$ \\
\hline$A \times B$ & 610.04 & 1.5 & 1 & 610.04 & 1.5 & 0.10 & 0.09 \\
\hline$C$ & 10880.04 & 1472.67 & 1 & 10880.04 & 1472.67 & 1.76 & $93.13 * * *$ \\
\hline$D$ & 16172.04 & 912.67 & 1 & 16172.04 & 912.67 & 2.61 & $57.71 * * *$ \\
\hline$E$ & 319473.38 & 1.5 & 1 & 319473.38 & 1.5 & $51.563 * * *$ & 0.09 \\
\hline$e_{1}$ & 51987.04 & 1.5 & 1 & 51987.04 & 1.5 & \multirow{4}{*}{\multicolumn{2}{|c|}{$\begin{array}{l}F_{0.90}(1,17)=3.03 \\
F_{0.95}(1,17)=4.45 \\
F_{0.99}(1,17)=8.40\end{array}$}} \\
\hline$e_{2}$ & 53341.33 & 267.33 & 16 & 3333.83 & 16.71 & & \\
\hline$e$ & 105328.38 & 268.83 & 17 & 6195.79 & 15.81 & & \\
\hline$T$ & 651784.63 & 2841.33 & 23 & 28338.46 & 123.54 & & \\
\hline
\end{tabular}

Note: $e_{1}$ is error of empty column, $e_{2}$ is error of repetition, $e$ is total error, $T$ is the sum value. $* * * *$ and $* * *$ respectively means significant differenced at $p<0.1, p<0.05$ and $p<0.01$. The same below.

\subsubsection{Cutting quality}

Number of failed cutting stubbles (no cutting off or phloem tearing) was taken as the appraisal index of cutting quality, and the experimental result of number of failed stubbles in each group of orthogonal test and variance calculation for given repeat tests is as shown in Table 3; ANOVA of number of failed stubbles is shown in Table 4.

Through ANOVA of experimental result of number of failed stubbles, factors $C$ and $D$ were significant in significance level 0.01 , factors $A$ and $B$ were significant in significance level 0.05 , while factor $E$ and interaction $A \times B$ were not significant. It was shown in result that blade edge type and blade length were main factors that affected the cutting quality, and cutting speed and stalk feeding speed were secondary factors that affected the cutting quality, while influence of number of movable blade and interaction between cutting speed and stalk feeding speed on cutting quality were not significant. The best combination of cutting quality was $C 2 D 1 A 1 B 2$, 
i.e. faster cutting speed, lower stalk feeding speed, and serrated- long edge blade should be used.

The experimental result showed that cutting and feeding speed and geometrical shape of blade would have influence on the success rate of hemp cutting.

\subsubsection{Synthesis score}

Calculation should be taken based on the established score model (Equation (1)), test results and variance calculation of score of each group of orthogonal test are shown in Table 5; ANOVA of score analysis is shown as Table 6. For the degree of freedom of error in the empty column was only one, and variance of item $A, B$ and interaction item $A \times B$ were relatively small, $A, B$ and interaction $A \times B$ were classified as the errors to calculate the variance of corrected error.

Through variance analysis on experimental results of score, factor $C, D$ and $E$ were significant at significance level 0.05. The result showed that blade edge type, blade length and the number of movable blade were the factors that affected the score. The combination with the highest and best score was $D 1 C 2 E 1$, i.e., serrated-long edge blade and cutter with double movable blades should be applied.

Table 5 Variances calculation for scores

\begin{tabular}{|c|c|c|c|c|c|c|c|c|}
\hline \multirow{2}{*}{ Table header } & $A$ & $B$ & $A \times B$ & $C$ & $D$ & $E$ & & \multirow{2}{*}{ Score $\mathrm{z}_{\mathrm{i}}$} \\
\hline & 1 & 2 & 3 & 4 & 5 & 6 & 7 & \\
\hline 1 & 1 & 1 & 1 & 1 & 1 & 1 & 1 & 67.21 \\
\hline 2 & 1 & 1 & 1 & 2 & 2 & 2 & 2 & 35.74 \\
\hline 3 & 1 & 2 & 2 & 1 & 1 & 2 & 2 & 46.45 \\
\hline 4 & 1 & 2 & 2 & 2 & 2 & 1 & 1 & 74.45 \\
\hline 5 & 2 & 1 & 2 & 1 & 2 & 1 & 2 & 40.00 \\
\hline 6 & 2 & 1 & 2 & 2 & 1 & 2 & 1 & 82.59 \\
\hline 7 & 2 & 2 & 1 & 1 & 2 & 2 & 1 & 33.50 \\
\hline 8 & 2 & 2 & 1 & 2 & 1 & 1 & 2 & 99.74 \\
\hline$T_{1}$ & 223.85 & 225.54 & 236.19 & 187.16 & 295.99 & 281.4 & 257.75 & \\
\hline$T_{2}$ & 255.83 & 254.14 & 243.49 & 292.52 & 183.69 & 198.28 & 221.93 & $T=479.68$ \\
\hline$k_{2}$ & 63.96 & 63.56 & 60.87 & 73.13 & 45.92 & 49.57 & 55.48 & $S_{T}=4224.79$ \\
\hline$S$ & 127.85 & 102.25 & 6.67 & 1387.60 & 1576.42 & 863.62 & 160.39 & \\
\hline
\end{tabular}

Note: $z_{i}$ is the score of No.i test level combination.

Table 6 ANOVA for scores

\begin{tabular}{|c|c|c|c|c|}
\hline Source & Sum of squares & $d f$ & Mean square & $F$-ratio \\
\hline$A$ & 127.85 & 1 & 127.85 & \\
\hline$B$ & 102.25 & 1 & 102.25 & \\
\hline$A \times B$ & 6.67 & 1 & 6.67 & \\
\hline$C$ & 1387.60 & 1 & 1387.60 & $13.98 * *$ \\
\hline$D$ & 1576.42 & 1 & 1576.42 & $15.88^{* *}$ \\
\hline$E$ & 863.62 & 1 & 863.62 & $8.70 * *$ \\
\hline$e$ & 160.39 & 1 & 160.39 & $F_{0.90}(1,4)=4.55$ \\
\hline Crt.e & 397.15 & 4 & 99.29 & $F_{0.95}(1,4)=7.71$ \\
\hline$T$ & 4224.79 & 7 & 464.45 & $F_{0.99}(1,4)=21.20$ \\
\hline
\end{tabular}

Note: $e$ is error, Crt. $e$ is corrected error.

\section{Quadratic regression of orthogonal rotating combinatorial test}

\subsection{Determination of factors and levels}

Among five factors of bench test, blade edge type $(C)$, blade length $(D)$ and number of movable blade $(E)$ are obtained by type selection, and level number is fixed as two, and only cutting speed $(A)$ and stalk feeding speed $(B)$ are continuous variables which could be obtained by regulated by transducer. Therefore, two factors would be chosen to perform the test in the quadratic regression of orthogonal rotating combinatorial test: cutting speed $(A)$ and stalk feeding speed $(B)$. Other factors that were not involved in the quadratic regression of orthogonal 
rotating combinatorial test should be fixed as the best level combination of score value in the orthogonal test.

According to methods of quadratic regression of orthogonal rotating combinatorial test ${ }^{[30]}$, the test number $n$ should meet the following equation:

$$
n=m_{c}+2 p+m_{0}
$$

where, $p$ is number of test factors, and that is 2 in this test; $2 p$ is the number of test point on the sphere with diameter $\rho=\gamma$ in the scope of canonical variate, and $\gamma$ is the asterisk arm; $m_{c}$ is the number of test point on the sphere with diameter $\rho=p^{0.5}$ in the scope of canonical variate; $m_{0}$ is the number of test point in the center of factor domain.

When $p=2$, the design parameters could be concluded by querying the parameter table of quadratic regression of orthogonal rotating combinatorial test that: $\gamma=1.414, m_{0}=5$, which totally needed 16 times. When quadratic orthogonal design is conducted directly, coding will be performed as follows:

The value range can be set as:

$$
x_{1 j} \leq x_{j} \leq x_{2 j} \quad j=1,2, \ldots p
$$

Now, let the code value of $x_{1 j}$ and $x_{2 j}$ be $-\gamma$ and $\gamma$, so the zero level is:

$$
x_{0 j}=\frac{x_{1 j}+x_{2 j}}{2} \quad j=1,2, \ldots p
$$

Radius is:

$$
\Delta_{j}=\frac{x_{2 j}-x_{1 j}}{2 \gamma} \quad j=1,2, \ldots p
$$

Then the code value -1 and 1 should respectively correspond to $x_{0 j}-\Delta_{j}$ and $x_{0 j}+\Delta_{j}$.

The code table of factors in the test is shown in Table 7.

Table 7 Factors and levels of the test

\begin{tabular}{ccc}
\hline Factor & Cutting speed $x_{1} / \mathrm{m} \cdot \mathrm{s}^{-1}$ & Stalk feeding speed $x_{2} / \mathrm{m} \cdot \mathrm{s}^{-1}$ \\
\hline Radius $\Delta$ & 0.2828 & 0.2121 \\
$-\gamma$ & 0.8000 & 0.5000 \\
-1 & 0.9172 & 0.5879 \\
0 & 1.2000 & 0.8000 \\
1 & 1.4828 & 1.0121 \\
$\gamma$ & 1.6000 & 1.1000 \\
\hline
\end{tabular}

Note: $\gamma$ is asterisk arm, and value is 1.414 .

\subsection{Results and analysis}

\subsubsection{Test results}

Three tests were repeated for each level combination.

For the convenience of recording and calculation, decimals were cut down as far as possible. The cutting power and number of failed stubbles were analyzed with the sum of three tests. Table 8 shows the sum of evaluation indexes in the three repeated tests. At this time, the cutting power is equal to the cutting power under the swath of $3 \mathrm{~m}$, and the number of failed stubbles is equal to the number of failed stubbles in $3 \mathrm{~m}^{2}$. In addition, the calculation method of synthesis score is the same as the calculation method of synthesis score in orthogonal test (as shown in Equation (1)).

Table 8 Results of test

\begin{tabular}{cccccc}
\hline Number & $\begin{array}{c}\text { Cutting } \\
\text { speed } \\
x_{1} / \mathrm{m} \cdot \mathrm{s}^{-1}\end{array}$ & $\begin{array}{c}\text { Stalk feeding } \\
\text { speed } \\
x_{2} / \mathrm{m} \cdot \mathrm{s}^{-1}\end{array}$ & $\begin{array}{c}\text { Cutting } \\
\text { power } \\
y_{1 i} / \mathrm{W}\end{array}$ & $\begin{array}{c}\text { Failed } \\
\text { stubbles } \\
y_{2 i}\end{array}$ & $\begin{array}{c}\text { Scores } \\
y_{3 i}\end{array}$ \\
\hline 1 & 1.4828 & 1.0121 & 1987 & 47 & 27.21 \\
2 & 1.4828 & 0.5879 & 2123 & 31 & 47.75 \\
3 & 0.9172 & 1.0121 & 1225 & 56 & 36.19 \\
4 & 0.9172 & 0.5879 & 1476 & 33 & 64.06 \\
5 & 0.8000 & 0.8000 & 1098 & 53 & 44.62 \\
6 & 1.6000 & 0.8000 & 2433 & 29 & 41.54 \\
7 & 1.2000 & 0.5000 & 1570 & 24 & 75.09 \\
8 & 1.2000 & 1.1000 & 1473 & 50 & 37.99 \\
9 & 1.2000 & 0.8000 & 1421 & 22 & 82.63 \\
10 & 1.2000 & 0.8000 & 1497 & 28 & 71.12 \\
11 & 1.2000 & 0.8000 & 1579 & 21 & 79.43 \\
12 & 1.2000 & 0.8000 & 1326 & 19 & 90.09 \\
13 & 1.2000 & 0.8000 & 1373 & 17 & 91.76 \\
14 & 1.2000 & 0.8000 & 1421 & 27 & 74.93 \\
15 & 1.2000 & 0.8000 & 1385 & 22 & 83.70 \\
16 & 1.2000 & 0.8000 & 1311 & 19 & 90.54 \\
\hline
\end{tabular}

\subsubsection{Regression model}

According to the test result of Table 8, DPS software ${ }^{[31]}$ was applied to conduct quadratic polynomial stepwise regression analysis for data, and consequently to obtain regression models of cutting power, number of failed stubbles and synthesis score.

$$
\begin{aligned}
y_{1}= & 4776.4502-4641.70453 x_{1} \\
& -3320.15280 x_{2}+2381.438460 x_{1}^{2} \\
& +1522.557263 x_{2}^{2}+479.311419 x_{1} x_{2} \\
y_{2}= & 283.854012-304.0589078 x_{1} \\
& -213.7141215 x_{2}+128.1398606 x_{1}^{2} \\
& +183.3597522 x_{2}^{2}-29.17547766 x_{1} x_{2} \\
y_{3}= & -420.67645+606.756950 x_{1} \\
& +428.217252 x_{2}-268.4581925 x_{1}^{2} \\
& -327.703453 x_{2}^{2}+30.55089304 x_{1} x_{2}
\end{aligned}
$$

where, $y_{1}$ is cutting power, $\mathrm{W} ; y_{2}$ is number of failed stubbles; $y_{3}$ is synthesis score; $x_{1}$ is cutting speed, $\mathrm{m} / \mathrm{s} ; x_{2}$ 
is the stalk feeding speed, $\mathrm{m} / \mathrm{s}$.

\subsubsection{Model test}

\section{(1) Fitting}

By using the DPS software, in the regression equation of cutting power in Equation (8), it calculated and obtained that correlation coefficient $R=0.972585$, determination coefficient $R^{2}=0.9459$, residual standard deviation $S S E=99.2863$, adjusted correlation coefficient $R_{a}=0.958583$; in the regression equation of number of failed stubbles in Equation (9), it calculated and obtained that correlation coefficient $R=0.962802$, determination coefficient $R^{2}=0.9270$, residual standard deviation $S S E=4.3180$, adjusted correlation coefficient $R_{a}=0.943654$; in the regression equation of scores in Equation (10), it calculated and obtained that correlation coefficient $R=0.963107$, determination coefficient $R^{2}=0.9276$, residual standard deviation $S S E=7.2991$, adjusted correlation coefficient $R_{a}=0.944120$. Overall data of regression model reflected that regression equation was equipped with high degree of fitting.

(2) $F$-examination

$F$-examination could reflect the significance of regression equation and Table 9 is ANOVA table of regression model.

According to Table $9, F$-examination of regression model of cutting power was 34.9831 , and the significant level $p$ was 0.0000 , which were respectively larger than $F$ in the loss-faulty test, i.e. 1.8422 and far less than $p$ in the loss-faulty test, i.e. 0.2275 . Therefore, the model could be applied.

Table 9 ANOVA of regression model

\begin{tabular}{|c|c|c|c|c|c|c|}
\hline Index & Source of variation & Sum of squares & $d f$ & Mean square & $F$ value & $p$ value \\
\hline \multirow{5}{*}{ Cutting power } & Regression & 1724276.0509 & 5 & 344855.2102 & 34.9831 & 0.0000 \\
\hline & Residual & 98577.6991 & 10 & 9857.7699 & & \\
\hline & Testing lack of fit & 43490.8241 & 3 & 14496.9414 & 1.8422 & 0.2275 \\
\hline & Error & 55086.8750 & 7 & 7869.5536 & & \\
\hline & Total & 1822853.7500 & 15 & & & \\
\hline \multirow{4}{*}{$\begin{array}{l}\text { Number of failed } \\
\text { stubbles }\end{array}$} & Residual & 186.4540 & 10 & 18.6454 & & \\
\hline & Testing lack of fit & 81.5790 & 3 & 27.1930 & 1.8150 & 0.2322 \\
\hline & Error & 104.8750 & 7 & 14.9821 & & \\
\hline & Total & 2553.7500 & 15 & & & \\
\hline \multirow{4}{*}{ Score } & Regression & 6823.4164 & 5 & 1364.6833 & 25.6149 & 0.0000 \\
\hline & Residual & 532.7686 & 10 & 53.2769 & & \\
\hline & Error & 403.4834 & 7 & 57.6405 & & \\
\hline & Total & 7356.1850 & 15 & & & \\
\hline
\end{tabular}

Test value in the regression model of number of failed stubbles is 25.3928 and the significant level $p$ was 0.0000 , which were respectively larger than $F$ in the loss-faulty test, i.e. 1.8150 and far less than $p$ in the loss-faulty test, i.e. 0.2322. Therefore, the model could be applied.

Test value in the regression model of number of failed stubbles was 25.6149 and the significant level $p$ was 0.0000 , which were respectively larger than $F$ in the lossfaulty test, i.e. 0.7477 and far less than $p$ in the loss-faulty test, i.e. 0.5572. Therefore, the model could be applied.

(3) Durbin-Watson statistic

Durbin-Watson statistic (D-W statistic) is the magnitude that is used to estimate whether residual distribution will follow normal distribution or not, and normal distribution characteristics of residual is one of the reference values to inspect whether regression model is applied or not. When D-W statistic is 2, it meant that residual distribution is consistent with normal distribution, so if $\mathrm{D}-\mathrm{W}$ statistic is close to 2 , then the established regression model will be more consistent with the real condition. By calculation of DPS software, D-W statistic of regression model of cutting power was 2.1019, and that of number of failed stubbles was 1.9520, and that of scores was 1.8748. Therefore, the value met the requirement, and the established model was close to the real condition.

\subsubsection{Optimum values of model}

The surface of regression model is drawn as Figure 6. 
Optimum values on the surface of regression model of cutting power were $(0.8788,0.9520,1156.5946)$; that of number of failed stubbles were $(1.2642,0.6834,18.6331)$; that of score were $(1.1704,0.7079,85.9558)$.
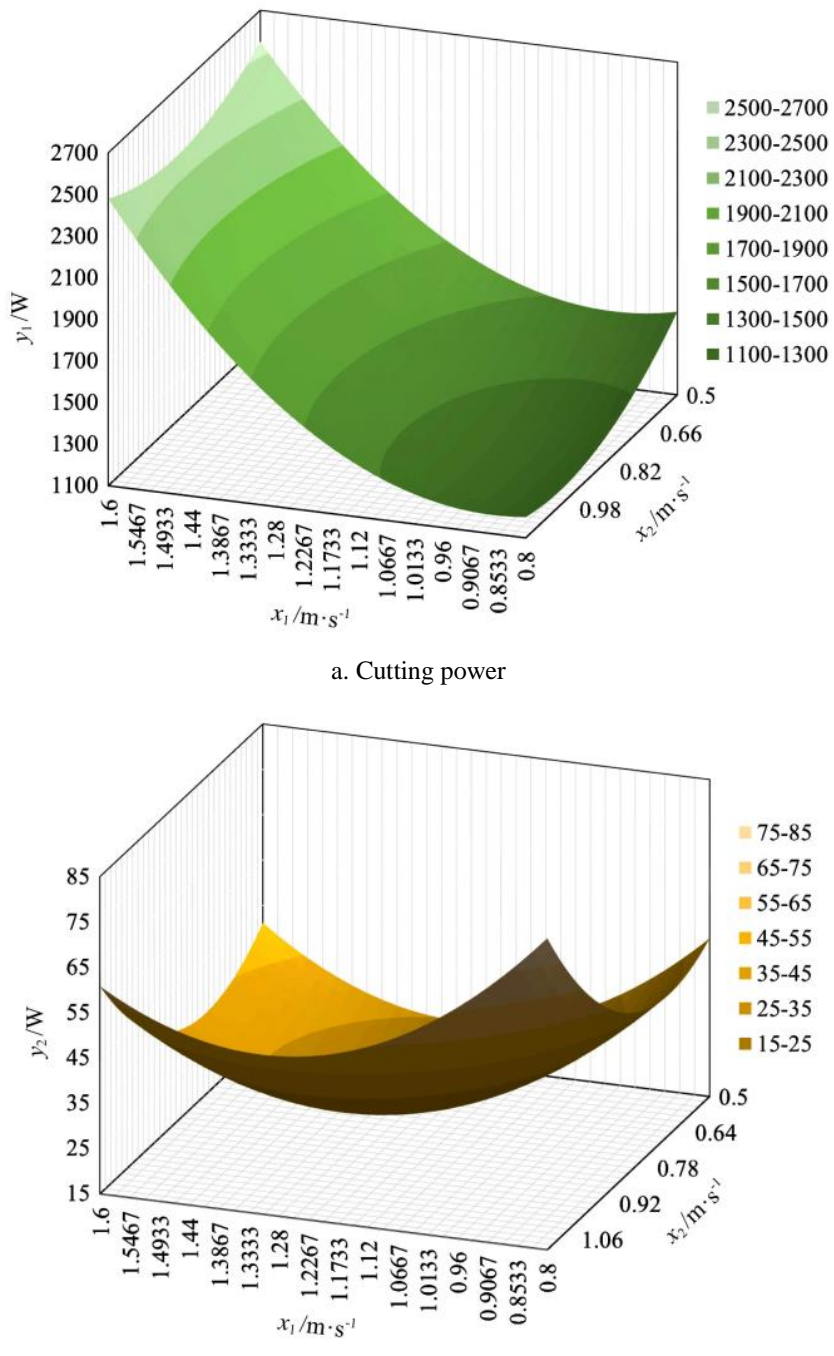

b. Number of failed stubbles

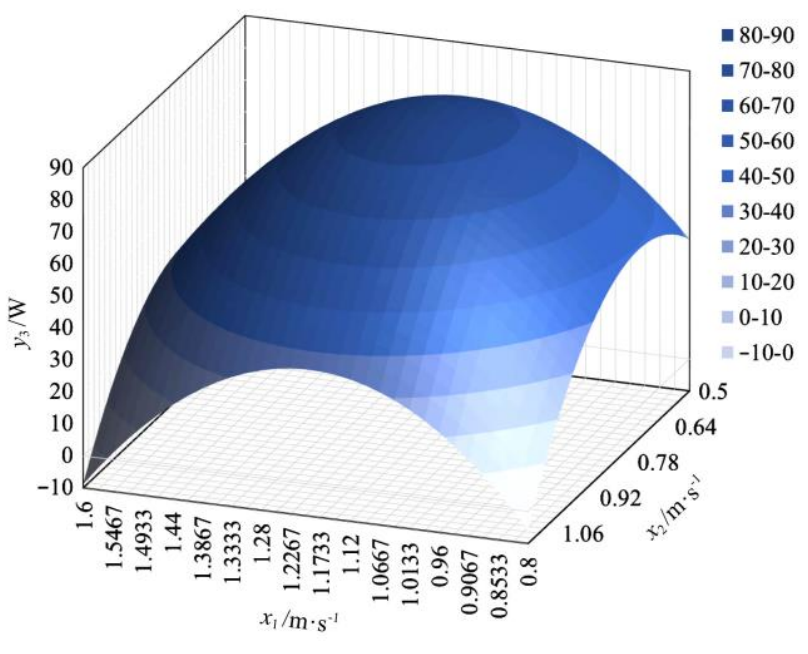

c. Score

Note: $y_{1}$ is cutting power, $y_{2}$ is number of failed stubbles, $y_{3}$ is score, $x_{1}$ is cutting speed, $x_{2}$ is stalk feeding speed.

Figure 6 Surface of regression mode of cutting power, number of failed stubbles and score
In conclusion, for cutting power, when cutting speed was $0.8788 \mathrm{~m} / \mathrm{s}$, stalk feeding speed was $0.9520 \mathrm{~m} / \mathrm{s}$, cutting power would be minimum, i.e. $1156.5946 \mathrm{~W}$ (for $3 \mathrm{~m}$ swath, equal to $385.5315 \mathrm{~W} / \mathrm{m}$ ); for cutting quality, the evaluation index was number of failed stubbles (no cutting off or phloem tearing), and when cutting speed was $1.2642 \mathrm{~m} / \mathrm{s}$, stalk feeding speed was $0.6834 \mathrm{~m} / \mathrm{s}$, the number of failed stubbles would be minimum, i.e. 18.6331 (in $3 \mathrm{~m}^{2}$ area, equal to $6.2110 / \mathrm{m}^{2}$ ); for synthesis score, when cutting speed was $1.1704 \mathrm{~m} / \mathrm{s}$, stalk feeding speed was $0.7079 \mathrm{~m} / \mathrm{s}$, the score was highest, i.e. 85.9558 , at this situation, the cutting power was $1415.7523 \mathrm{~W}$ (equal to $471.9177 \mathrm{~W} / \mathrm{m}$ ), and the number of failed stubble was 19.9389 (equal to $6.6463 / \mathrm{m}^{2}$ ).

\subsubsection{Analysis}

The cutting power is mainly comprised of driving power of cutter and the power of stalk being cut off. When the cutting speed is high, the cutting power will be great. Theoretically, the driving power of cutter is in direct proportion to the square of speed, and increases sharply with the rise of cutting speed. Such phenomenon is also reflected in the test results. In addition, in terms of the stalk feeding speed, if the stalk feeding speed is high, more hemp stubbles can be cut, and the work consumed by material damage will be great. In theory, the stalk material damage power is in direct proportion to the stalk feeding speed. But the model surface of test results shows that the factor of stalk feeding speed does not have a huge influence on the cutting power. Therefore, it is obtained that cutting power is generated by driving power of cutter to a great extent, while the influence of power produced by hemp stalk material damage is relatively small.

As for the number of failed stubbles, when the cutting speed is low and stalk feeding speed is high, some hemp stalks will be transported before cutting, so cutting failure will happen easily. On the contrary, when the cutting speed is high and stalk feeding speed is low, the phenomenon of repeated cutting will happen, and the cutting stubbles might be torn or destroyed easily. The test results also reflected this phenomenon. Therefore, the theoretical optimum speed combination with the minimum number of failed stubbles should be selected according to the test. 
In terms of the score, the speed combination with optimum score is closer to the speed combination with optimum number of failed stubbles, and cutting quality has a greater influence on the synthesis score than cutting power. As for the reason, the weight of cutting quality selected in evaluation model establishment is higher.

\section{Conclusions}

(1) In order to obtain the optimal parameters of cutter for design of the hemp harvester, cutting tests (Multi-factors orthogonal test and quadratic regression of orthogonal rotating combinatorial test) on hemp stalk were conducted in this study.

(2) Multi-factors orthogonal test was applied in the bench test using the self-designed test bench; according to the test objective, the influences of cutting speed, stalk feeding speed, blade edge type, blade length and number of movable blade on cutting power, cutting quality and synthesis score were examined. For cutting power, factors with significant influence were number of movable blade, and cutting speed in order of significance, and the best level combination was that the cutting speed should be slow $(0.8 \mathrm{~m} / \mathrm{s})$, and cutter of reciprocating double movable blades should be applied, in addition that stalk feeding speed, blade length and type of blade edge have no significant influence on cutting power; for cutting quality, taken cutting failed stubbles (no cutting off or phloem tearing) as the appraisal index, factors with significant influence were respectively type of blade edge, blade length, cutting speed and stalk feeding speed in order of significance, and the best combination was that using serrated-edge blade and long blade $(120 \mathrm{~mm})$, with fast cutting speed $(1.2 \mathrm{~m} / \mathrm{s})$ and low stalk feeding speed $(0.6 \mathrm{~m} / \mathrm{s})$. In addition, influence of number of movable blade on cutting quality was not significant; for synthesis score, factors with significant influence were respectively blade length, type of blade edge and number of movable blade in order of significance, and the best level combination was that long $(120 \mathrm{~mm})$ serrated edge blade and cutter of reciprocating double movable blade.

(3) Combined with the level combination with highest score in the orthogonal test, quadratic regression of orthogonal rotating combinatorial test was conducted on the two groups of parameters which could be adjustable continuously, i.e. cutting speed and stalk feeding speed, to examine the influence of cutting speed, stalk feeding speed and mutual effect of these two factors on cutting power, cutting quality and synthesis score, and to build the quadratic regression function respectively. The optimal solution could be gained from regression function. For cutting power, when cutting speed was $0.8788 \mathrm{~m} / \mathrm{s}$, stalk feeding speed $0.9520 \mathrm{~m} / \mathrm{s}$, the cutting power was minimum, i.e. $385.5315 \mathrm{~W} / \mathrm{m}$; for cutting quality, taken cutting failed stubbles as the appraisal index, when cutting speed was $1.2642 \mathrm{~m} / \mathrm{s}$, stalk feeding speed $0.6834 \mathrm{~m} / \mathrm{s}$, the number of cutting failed stubbles was smallest, i.e. $6.2110 / \mathrm{m}^{2}$; for synthesis score, when cutting speed was $1.1704 \mathrm{~m} / \mathrm{s}$, stalk feeding speed $0.7079 \mathrm{~m} / \mathrm{s}$, the score was highest, i.e. 85.9558, and at this situation, the cutting power was $471.9177 \mathrm{~W} / \mathrm{m}$, the number of failed stubble was $6.6463 / \mathrm{m}^{2}$.

(4) The tests results showed that the best combination of hemp cutting test was that using cutter of reciprocating double movable blades and long $(120 \mathrm{~mm})$ serrated edge blade with cutting speed of $1.1704 \mathrm{~m} / \mathrm{s}$, stalk feeding speed of $0.7079 \mathrm{~m} / \mathrm{s}$. The optimal parameters combination of hemp cutting adopted in the test was reasonable, and experimental analysis results can be applied into subsequent related researches on hemp harvester.

\section{Acknowledgments}

We greatly appreciate the careful and precise reviews by the anonymous reviewers and editors. This research was financially supported by the National Key R\&D Program of China (2016YFD0701405-02), China Agriculture Research System for Bast and Leaf Fiber Crops (CARS-19-E22) and the Agricultural Science and Technology Innovation Program of Chinese Academy of Agricultural Sciences (ASTIP, CAAS).

\section{[References]}

[1] Leaf Science. Five differences between hemp and marijuana. Available at: http://www.leafscience.com/2014/09/16/5differences-hemp-marijuana. Accessed on [2014-09-16]

[2] Karus M, Vogt D. European hemp industry: cultivation, processing and product lines. Euphytica, 2004; 140(1-2): 7-12.

[3] House J D, Neufeld J, Leson G. Evaluating the quality of 
protein from hemp seed (Cannabis sativa L.) products through the use of the protein digestibility-corrected amino acid score method. Journal of Agricultural and Food Chemistry, 2010; 58(22): 11801-11807.

[4] Zhou Y, Li X W, Shen C, Tian K P, Zhang B, Huang J C. Experimental analysis on mechanical model of industrial hemp stalk. Transactions of the CSAE, 2016; 32(9): 22-29. (in Chinese)

[5] Kymäläinen H R, Sjöberg A M. Flax and hemp fibers as raw materials for thermal insulations. Building and Environment, 2007; 42(3): 1016-1024.

[6] Sun X Y, Guan Y T, Wen G Q, Zhu B Y. Study on the characteristics of hemp and its applications. Journal of Textile Research, 2001; 22(4): 234-236. (in Chinese)

[7] Muzyczek M, Kozłowski R M. The use of flax and hemp for textile applications. Handbook of Natural Fibres: Processing and Applications, 2012; pp.312-328. ISBN 1845696980.

[8] Dai F J. Studies on the origin, uses and geographical distribution of hemp. Journal of Southwest China Normal University (Natural Science), 1989; 14(3): 114-119. (in Chinese)

[9] Liu H. Study on factors affecting yield of industrial hemp. MS Dissertation, Kunming: Yunnan University, 2015; China. (in Chinese)

[10] Lü J N, Long C H, Ma L, Liu J J, He H B. Design and experiment on decorticator of hemp fresh stem. Transactions of the CSAE, 2014; 30(14): 298-307. (in Chinese)

[11] National Bureau of Statistics of China. 12-11 Output of major farm products per hectare. China Statistical Yearbook 2016. 2016; pp.397. ISBN 9787503779176 . (in Chinese)

[12] Shen C, Chen Q M, Li X W, Tian K P, Huang J C, Zhang B. Experimental analysis on single-stalk cutting of hemp. International Agricultural Engineering Journal, 2016; 25(4): 187-196.

[13] Shen C, Li X W, Tian K P, Zhang B, Huang J C, Chen Q M. Experimental analysis on mechanical model of ramie stalk. Transactions of the CSAE, 2015; 31(20): 26-33. (in Chinese)

[14] Zhou Y, Shen C, Li X W, Zhang B, Huang J C, Tian K P. Design and test of 4LMD-160 hemp harvester. Applied Mechanics and Materials, 2016; 851: 389-395.

[15] Shen C, Li X W Zhang B Tian K P, Huang J C, Chen Q M. Bench experiment and analysis on ramie stalk cutting. Transactions of the CSAE, 2016; 32(1): 68-76. (in Chinese)

[16] Shen C, Zhang B, Tian K P, Li X W, Chen Q M. Test and analysis on axial compressive mechanics of ramie stalk. International Journal of Engineering and Technology, 2017; 9(6): 432-436.

[17] Zhao Z, Li Y M Xu L Z, Song S J. Experiment on Cutting Mechanical Property of Single Super Rice Stalk. Transactions of the CSAM, 2010; 41(10): 72-75. (in Chinese)

[18] Zhang S F, Song Z H, Yan Y F, Li Y D, Li F D.
Development and experiment of measure and control system for stalk cutting test bench. Transactions of the CSAE, 2013; 29(Supp.1): 10-17. (in Chinese)

[19] Liu Q T, Ou Y G, Qing S L, Huang S X. High-speed photography analysis on the damage process in cutting sugarcane stalk with smooth-edge blade. Transactions of the CSAM, 2007; 38(10): 31-35. (in Chinese)

[20] Li Y M, Qing T D, Chen J, Zhao Z. Experimental study and analysis on mechanical property of corn stalk reciprocating cutting. Transactions of the CSAE, 2011; 27(1): 160-164. (in Chinese)

[21] Gupta C P, Oduori M F. Design of the revolving knife-type sugarcane base cutter. Transactions of the ASAE, 1992, 35(6): 1747-1752.

[22] Liu Z P. Design and study on disc cutter of ramie. MS Dissertation, Changsha: Hunan Agricultural University, 2011 China. (in Chinese)

[23] Liao Q X, Shu C X, Tian B P, Huang H D, Wang J. Research on the cutting process based on high- speed photography technology for the arundo donax 1. Journal of Huazhong Agricultural University, 2007; 26(3): 415-418. (in Chinese)

[24] McRandal D M, MeNulty P B. Impact cutting behavior of forage crops mathematical model and laboratory tests. Journal of Agricultural Engineering Research, 1978; 23(3): 313-328.

[25] Finner M F. Particle movement through the cutter-head of a cylindrical type forage harvester. Transactions of the ASAE, 1975; 18(6): 1017-1020.

[26] Shen C, Chen Q M, Li X W, Zhang B, Wang J G, Huang J C, et al. Design and experiment on double-knife ramie stalk cutting test bench. Journal of Chinese Agricultural Mechanization, 2013; 34(5): 114-118. (in Chinese)

[27] Chen, Y, Jean L G, Liu J. Power requirements of hemp cutting and conditioning. Biosystems Engineering, 2004; 87(4): 417-424.

[28] Sausserde R, Adamovics A, Ivanovs S, Bulgakov V. Investigations into growing and harvesting industrial hemp. Journal of Research \& Applications in Agricultural Engineering, 2013; 58(4): 150-154.

[29] Wang Y F, Qiu C S, Hao D M, Chen X B, Long S H, Deng X, et al. Production status and developmental direction of hemp in China. Modern Agricultural Science and Technology, 2009; (23): 84-86.

[30] Ren L Q. Quadratic regression of orthogonal rotating combinatorial design. Regression Design and its optimization. 2009; pp.40-49. ISBN 9787030254344. (in Chinese)

[31] Tang Q Y, Zhang C X. Data Processing System (DPS) software with experimental design, statistical analysis and data mining developed for use in entomological research. Insect Science, 2013; 20(2): 254-260. 